\title{
Relationship Between Vital Signs, Hemoglobin Level and Iron Consumption Pattern With Learning Concentration
}

\author{
Tutiek Rahayu $^{1 *}$, Tri Harjana ${ }^{1}$, Kartika Ratna Pertiwi ${ }^{1}$, Yuliati $^{1}$ \\ ${ }^{1}$ Department of Biology Education, Faculty of Mathematics and Natural Science, Universitas Negeri Yogyakarta, \\ Indonesia \\ ${ }^{*}$ Corresponding author.Email: tutiek_rahayu@uny.ac.id
}

\begin{abstract}
This study aimed to determine the vital signs (pulse and respiratory rate), hemoglobin ( $\mathrm{Hb})$ levels and iron ( $\mathrm{Fe}$ ) consumption pattern, and to assess their correlation with learning concentration in adolescents. This cross-sectional study was conducted from June to September 2017. Thirty-five subjects were selected from students majoring Biology Education at Yogyakarta State University (UNY) using purposive sampling technique (aged 17-24 years old). Physical examination was performed to measure pulse and respiratory rate, while hemoglobin level was measured with easy touch hemoglobin meter. Iron consumption pattern was assessed with nutrient conversion table and food record (Indonesian Health Ministry guideline), alongside the nutrient survey program and Bourdon Wiersma study concentration test. Data were analyzed using Spearman Correlation Test. The results showed that: (1) normal pulse, respiration rate and blood pressure found in female subjects were approximately $84 \%, 40 \%$, and $91,67 \%$; whereas in male subjects were $90,01 \%, 55 \%$, and $81,81 \%$, respectively (2) $37 \%$ female subjects had $\mathrm{Hb}$ level of $>12 \mathrm{mg} / \mathrm{dl}$ and $100 \%$ male subjects had $>13 \mathrm{mg} / \mathrm{dl}$ (3) adequate iron consumption pattern according to the nutrition instruments used in this study was $96 \%$ in female and $90,01 \%$ in male (4) learning concentration results indicated that study concentration was $45,71 \%$ in middle and $54,29 \%$ in lower category. In conclusion, there is correlation between study concentration with vital signs, i.e. pulse and respiratory rate, as well as with iron consumption pattern, but not with blood pressure nor $\mathrm{Hb}$ blood levels.
\end{abstract}

Keywords: Vital signs, pulse, respiratory rate, iron, learning concentration.

\section{INTRODUCTION}

Vital signs, such as pulse, respiratory rate, blood pressure and body temperature, are important in the assessment of physiological condition of human body. Cardiorespiratory endurance, a combination of pulse and respiratory rate, describes the ability of the lungs to supply oxygen throughout our cells (including the brain cells) for a long period of time. Blood pressure and body temperature are not only important in the heart and respiratory systems but are also important to be maintained so that all activities of a mankind could run well, including the thinking process within a learning activity.

In addition, hemoglobin $(\mathrm{Hb})$ blood level should also be monitored in order to assess the presence of health problems such as anemia. Iron deficiency anemia still becomes a national nutritional problem in adult and adolescence in Indonesia. Therefore, periodic measurement of $\mathrm{Hb}$ blood level is important for the early detection of iron deficiency anemia.

Iron deficiency anemia in adolescent is related to the nutrient consumption pattern. Most iron deficiency anemia is resulted from the inadequate consumption of iron, which is not in accordance with the concept of balanced nutrition. Our previous study encountered that in 2016, during the blood donation program, a part of Dies Natalis Anniversary of Yogyakarta State University (UNY), half of the potential donor candidates (278 students) failed to donate their blood due to their low $\mathrm{Hb}$ level. This indicates iron deficiency 
anemia, which is characterized by blood level of $\mathrm{Hb}$ less than $12 \mathrm{mg} / \mathrm{dl}$.

A normal physiological state of human body is necessary to perform daily activities, including learning. Learning process is an important factor that needs to be considered in human development, therefore for the preparedness of learning, concentration is of importance. Concentration learning means a mindful of concentration or full attention during learning process. It is influenced by internal and external factors. Internal factor such as physiological condition can be reflected from vital signs or health condition that should be in accordance to health standards. Based on the database of Health Clinic of Yogyakarta State University (UNY), the major complaints of students during the last three years were dizziness, drowsiness, sore throat, influenza and stomach disorders. These various health-related complaints can cause concentration difficulty in learning. Meanwhile, external conditions include learning environment and learning facilities.

One internal effort to improve the learning concentration is to maintain normal physiological conditions, physical exercise and with the support of a balanced nutritious food intake. Henti Sukesti (2008) studied that nutritional factors of daily food contribute $57,80 \%$ to the concentration of nursing student at Health Institute of Dharma Husada Bandung [1]. In line with this, Veny Indrawati (2004) reported that anemia affects the concentration of learning in primary school children [2]. Similarly, Saidin (1991) previously suggested that there is a relationship between breakfast intake and anemia with learning concentration in primary school students [3].

To date, there has been little information on the relationship between vital signs, $\mathrm{Hb}$ blood levels and iron consumption pattern with learning concentration especially in adolescents. In this regard, Biology students at the Faculty of Mathematics and Natural Science, Yogyakarta State University (UNY) really need high concentration for laboratory activities. Activities in the laboratory require precision, accuracy and perseverance as such learning concentration is of importance. The purposes of this study were to determine the blood level of $\mathrm{Hb}$, to investigate the consumption pattern of iron $(\mathrm{Fe})$ in the daily diet and to assess the learning concentration of students majoring Biology Education at YSU. In addition, the relationship between vital signs, $\mathrm{Hb}$ blood level and iron consumption with the learning concentration was subsequentially assessed.

\section{MATERIALS AND METHODS}

The participants of this study were purposively selected from students majoring Biology Education who undertook Human Biology course at their third year. All participants were in healthy conditions, not under medication or dietary supplements, and actively attending lectures as well as lab works on daily basis. Female were chosen to be the same condition as male, thus only female that were not in their menstruation period could participate in this research.

In this study, the tools used to measure vital signs were aneroid sphygmomanometer (Onemed) and stethoscope (GEA) for blood pressure test, $\mathrm{Hb}$ meter (easy touch) for $\mathrm{Hb}$ level, and stopwatch (bodytronics) for pulse and respiratory rate. Food record form including the source of iron nutrients were filled by participants, recording their diet for 3 consecutive days. Bourdon Wiersma study concentration test was performed to assess learning concentration.

This study consisted of several steps including preparation, implementation, data analysis and discussion. The preparation stage included the arrangement and approval of study and ethical permits from Yogyakarta State University (UNY), population surveys and sampling. Preparation step included instrument preparation to measure vital signs, Hb levels as well as iron consumption patterns and learning concentrations. Measurement of vital signs was performed by two independent examiners in a group of 4 participants during implementation. Physical examination was conducted to measure pulse and respiratory rate per minute, followed by measurement of blood pressure and $\mathrm{Hb}$ levels. Consumption patterns of iron nutrients and concentration of learning were subsequently assessed. The collected data was then analyzed descriptively and correlation between variables was analyzed using SPSS (SPSS ver. 22).

\section{RESULT AND DISCUSSION}

This research aimed to know the correlation between vital signs, which are pulse, respiration rate, blood pressure (both systole and diastole), consumption pattern of iron nutrient and blood hemoglobin level with study concentration in research subjects, in this regard the students majoring Biology Education Department at their third year in Faculty of Mathematics and Natural Science, Yogyakarta State University (UNY), whose age still belongs to adolescent age group.

\subsection{Study Participants}

The participants in this study were 35 students at the third year of Biology Education. They consisted of 24 women and 11 men (table 1). The number of female participants was twice more than men, with their age ranged between 19-20 years. In average, the students' daily activity was categorized as moderate, i.e. on campus and light exercise. Their learning concentration was mostly categorized as less (around 54, 29\% students) while the rest was categorized as medium. 
Table 1. Number of participants based on gender

\begin{tabular}{|l|c|c|}
\hline \multicolumn{1}{|c|}{ Gender } & Total & Proportion (\%) \\
\hline Female & 24 & 69,44 \\
\hline Male & 11 & 30,56 \\
\hline
\end{tabular}

Overall, participants who fulfilled the questionnaires, stated that they had never experienced any serious complaints of illness. Most students claimed to have suffered influenza in the past. In addition, subjects had sleep ranged from 4-9 hours per day, with an average of 6 hours per day. Another finding revealed that most research subjects have a drinking tea habit any time per day. Most participants drink 3-4 cups of tea each day while only 8 subjects drink tea occasionally. This is important to point out, because the drinking habit of beverages containing tannins (such as tea and coffee) would affect iron absorption in the body. Consuming a high concentration of tannin tend to lower the rate of iron absorption in the intestine.

\subsection{Measurement of Hemoglobin, Body Mass Index and Iron Consumption}

Hemoglobin blood $(\mathrm{Hb})$ levels obtained from participants are presented in Table 2. There were 63\% female students whose $\mathrm{Hb}$ level could be categorized as abnormal. Meanwhile, Hb levels in male subjects were all within normal range, which was more than or equal to $13 \mathrm{mg} / \mathrm{dl}$.

Table 2. Hemoglobin blood levels of participants

\begin{tabular}{|c|c|c|c|c|}
\hline \multirow{2}{*}{ Gender } & \multirow{2}{*}{ Total } & \multirow{3}{|c|}{ Hb $(\mathrm{g} / \mathrm{dl})$} \\
\cline { 3 - 5 } & & \multirow{2}{*}{ Average } & \multicolumn{2}{|c|}{ Proportion (\%) } \\
\cline { 3 - 5 } & & Normal & Abnormal \\
\hline Female & 24 & 11,73 & 37 & 63 \\
\hline Male & 11 & 15,56 & 100 & 0 \\
\hline
\end{tabular}

The body mass index and iron nutrient consumption of the participants are shown in Table 3. This table describes the nutritional status of the participants, as per indicated by their Body Mass Index (BMI). BMI could be calculated by dividing weight $(\mathrm{kg})$ per square of body height $(\mathrm{m})$. In average, participants had BMI which were belong to moderate, not thin nor obese.

Table 3. Body Mass Index (BMI) and Iron Nutrient Consumtion

\begin{tabular}{|c|c|c|c|}
\hline \multicolumn{2}{|c|}{ Details of } & Female & Male \\
\hline \multicolumn{2}{|l|}{ Total } & 24 & 11 \\
\hline \multirow{2}{*}{$\begin{array}{l}\text { Average } \\
\text { BMI }\end{array}$} & Heigh $(\mathrm{cm})$ & 149,82 & 167,81 \\
\hline & Weigh (kg) & 51,79 & 59,81 \\
\hline \multicolumn{2}{|c|}{ Average Iron Consumption } & 6,50 & 6,33 \\
\hline \multirow{2}{*}{$\begin{array}{l}\text { Daily Iron } \\
\text { Intake }\end{array}$} & Adequate (\%) & 96,00 & 90,01 \\
\hline & $\begin{array}{l}\text { Inadequate } \\
(\%)\end{array}$ & 4,00 & 9,09 \\
\hline
\end{tabular}

The daily consumption of iron nutrients calculated using nutrition survey (recorded for $3 \times 24$ hours) showed that only $4.00 \%$ female and $9.09 \%$ men did not fulfill the Nutrient Adequate Numbers recommendation (Angka Kecukupan Gizi / AKG) of iron nutrient. Thus, only a small proportion of female and male subjects that lack of adequate iron intake in their daily diet. Daily need of absorbed iron in human body is calculated based on the amount of iron from food needed to overcome the basal loss due to menstruation (women) and for growth (all). Due to menstruation, women loss more iron and thus their daily need increases so that the demand for absorbed iron nutrient is around $1.4 \mathrm{mg}$ per day.

\subsection{Measurement of Vital Signs}

Findings on pulse measurement are depicted in table 4. Vital signs, in this regard the pulse are within normal range, around 60-100 beats per minute. In female, $26 \%$ participants had pulse outside the normal range, it was $9.09 \%$ in male. This observation indicates that in this study, the male participants were in better condition compared to the female ones.

Table 4. Measurement of Pulse

\begin{tabular}{|c|c|c|c|c|}
\hline \multirow{2}{*}{ Gender } & \multirow{2}{*}{ Total } & \multicolumn{3}{|c|}{ Pulse per Minute } \\
\cline { 3 - 5 } & & \multirow{2}{*}{ Average } & \multicolumn{2}{|c|}{ Proportion (\%) } \\
\cline { 3 - 5 } & & 79,92 & Normal & Abnormal \\
\hline Female & 24 & 83,09 & 90,01 & 26 \\
\hline Male & 11 & \multicolumn{3}{|c}{} \\
\hline
\end{tabular}

In line with the pulse findings, for the respiratory rate, most women $(60 \%)$ have abnormal breathing frequency. In contrast, there were only $45 \%$ male participants had abnormal respiratory rate. Normal respiratory rate at the age of the participants range from 20-30 minutes per minute under mild working conditions (Table 5).

Table 5. Measurement of Respiratory Rate

\begin{tabular}{|c|c|c|c|c|}
\hline \multirow{2}{*}{ Gender } & \multirow{2}{*}{ Total } & \multicolumn{3}{|c|}{ Respiratory Rate per Minute } \\
\cline { 3 - 5 } & & \multirow{2}{*}{ Average } & \multicolumn{2}{|c|}{ Proportion (\%) } \\
\cline { 3 - 5 } & & & Normal & Abnormal \\
\hline Female & 24 & 48,76 & 40 & 60 \\
\hline Male & 11 & 20,91 & 55 & 45 \\
\hline
\end{tabular}

Measurement of blood pressure (systole and diastole) showed that only a small part of the subjects had abnormal blood pressure. Normal blood pressure at the age of the participants, for systole / diastole is around 120/80 $\mathrm{mm} \mathrm{Hg}$. More abnormal blood pressure was found in male than in female. When compared to female participants, the number of male participants with abnormal blood pressure was nearly two and a half times higher (Table 6). 
Table 6. Measurement of Blood Pressure (Systole and Diastole)

\begin{tabular}{|l|l|c|c|}
\hline \multicolumn{2}{|c|}{ Details of } & Female & Male \\
\hline Total & 24 & 11 \\
\hline $\begin{array}{l}\text { Blood Pressure } \\
(\mathrm{mmHg})\end{array}$ & Systole & 107,6 & 109,54 \\
\cline { 2 - 4 } & Diastole & 73,8 & 74,09 \\
\hline Proportion (\%) & Normal & 91,67 & 81,81 \\
\cline { 2 - 4 } & Abnormal & 8,33 & 18,19 \\
\hline
\end{tabular}

\subsection{Correlation Between Vital Signs, Hemoglobin, Iron Consumption With Learning Concentration}

The findings from concentration test showed that lower learning concentration found in women and men were around $45.71 \%$ and $54.29 \%$, respectively. Correlation between pulse, respiratory rate, blood pressure (systole and diastole), iron intake and $\mathrm{Hb}$ level with study concentration was analyzed using SPSS and the results are shown in table 7. The results demonstrated that vital signs (pulse, respiratory rate and blood pressure) were positively correlated with learning concentration in moderate. In regard to intake of iron nutrients and $\mathrm{Hb}$ levels, their correlations with learning concentration were weakly positive, respectively. In contrast, negative correlations were found between blood pressure and $\mathrm{Hb}$ levels with learning concentration, respectively.

The weak relationship between iron consumption patterns and concentration of learning can be caused by several factors, one of which is the iron deficiency anemia. This condition occurs through three stages, which are stage I: depletion of iron reserves marked by a decrease in serum ferritin while measured hemoglobin and iron is still normal, stage II: iron deficiency without anemia when the iron reserves are exhausted, the iron levels in the serum will decrease and hemoglobin levels are still normal, and stage III: iron deficiency anemia marked by low level of blood hemoglobin.

Table 7. Correlation analysis between measured parameters and learning concentration

\begin{tabular}{|l|c|l|}
\hline \multicolumn{1}{|c|}{ Variable } & $\mathrm{R}$ & \multicolumn{1}{c|}{ Close Relatioship } \\
\hline Heart rate & 0,370 & Medium relationship \\
\hline $\begin{array}{l}\text { Respiratory } \\
\text { Frequency }\end{array}$ & 0,142 & Relationship weak \\
\hline Sistole & $-0,087$ & Relationships mean less \\
\hline Diastole & $-0,173$ & Relationship weak \\
\hline $\begin{array}{l}\text { Intake of Iron } \\
\text { Nutrition }\end{array}$ & 0,123 & Relationship weak \\
\hline $\begin{array}{l}\text { Hemoglobin } \\
\text { levels }\end{array}$ & $-0,013$ & Relationships mean less \\
\hline
\end{tabular}

Among five independent variables tested in this research, there were only 3 variables, pulse and respiratory rate (internal factors) and iron nutrients uptake (external factors), that influenced learning concentration, respectively. The concentration of learning can also be influenced by other factors such as motivation, of which is not measured in this study.

\subsubsection{Relationship Between Pulse and Respiratory Rate With Learning Concentration}

A total of $35.71 \%$ and of $48.58 \%$ subjects had pulse and respiratory rate within normal range, respectively. Learning concentration needs energy therefore if the heart and lungs can function well, then the oxygen required for the brain is fulfilled. On the other hand, the work intensity also affects the oxygen demand. The higher workload the more rate of breathing is needed, as such the heart rate will also be higher. When the oxygen demand increases, the pulse will also increase as a compensation so that it can still deliver optimal oxygen to all body cells. Thus, cardiorespiratory function is closely related to the adequacy of oxygen especially in the brain.

Activities trigger fatigue are closely related to concentration, job skills, and work efficiency [4], thus, there is a relationship between cardiorespiratory function with the respiratory and heart rate parameters as a measure of vital signs.

\subsubsection{Relationship of Consumption Pattern of Iron Nutrition With Learning Concentration}

When the iron consumption is in accordance with the Nutrient Adequate Numbers recommendation, the $\mathrm{Hb}$ blood can function better, so that $\mathrm{Hb} \mathrm{O} 2$ is fulfilled. Our findings showed that only $4 \%$ women and $9.09 \%$ men did not meet the recommended daily amount of iron nutrition. Overall, participants of our study had good intake of iron nutrients, which contribute to their good condition, and subsequently correlate with learning concentration. Supporting this, the findings of Body Mass Index (BMI) indicated that most participants were in the category of being normal, not fat nor skinny. Sunita Atmalsier (2009) emphasized that the adequate iron intake is necessary for the formation of $\mathrm{Hb}$, which are involved in the transport of oxygen within the blood and the transfer of electrons [5]. Iron is an important part of hemoglobin and is needed for synthesis of porphyrin hemoglobin. The most important substances needed by the brain are oxygen and glucose. Lack of oxygen and glucose may interfere with the production of adenosine tri phosphate and the substrate supply for neurotransmitter synthesis. Iron deficiency has a relationship with the enzyme aldehyde-oxidase in the brain which results in decreased ability to pay attention to something. Anemia also causes memory and concentration becomes low [2].

Concentration is one of the cognitive functions of the brain. Biologically, iron deficiency anemia can cause problems related to cognitive achievement. This is 
due to the decreased iron reserves in the body including iron reserves in the central haemopoetic system needed for red blood cell production. Decreased hemoglobin level in iron deficiency anemia compromises hemoglobin functions in transporting oxygen for metabolic reactions, processes needed for physical growth and brain development [6]. Thus, the adequacy of iron, associated with the fulfillment of oxygen needs in the brain, therefore there is correlation between iron uptake with learning concentration.

\subsubsection{Relationship Between Blood Pressure And Hb Level With Learning Concentrations}

Both blood pressure and $\mathrm{Hb}$ level are influenced by many factors. Although iron intake is sufficient, interaction between iron and inhibitors may complicate iron absorption. It could explain the reason why $\mathrm{Hb}$ level measured in this study had no association with learning concentrations.

\section{CONCLUSION}

Based on our findings, learning concentration in adolescents is influenced by pulse and respiratory rate as well as iron nutrient uptake. Therefore, abnormalities of pulse and respiratory rate, together with lacking of iron uptake appear to decrease learning concentration in our subjects. On the other hand, other independent variables which are blood pressure and $\mathrm{Hb}$ level have no relationship with learning concentration. Nevertheless, multiple regression analysis among measured parameters with learning concentration showed no significances $(\mathrm{p}>0.05)$. Thus, based on our findings, it can be stated that the independent variables cannot predict the dependent variable, the concentration of learning. Furthermore, this study also has limitations because there is no direct measurement of the activity performed by the participants, or the activity is not directly measured using the oxygen demand method i.e. using the calculation of vital capacity of the lungs. As such, the activity data relied only from the participants' answer in the questionnaire, and not as a measured variable.

\section{REFERENCES}

[1] S. Henti, F. Jahidun and N. Veronica, Nursing Science, Bandung, Stikes Dharma Husada, 2008.

[2] I. Veny, Effect of Anemia on Learning Concentration of Elementary School Children, in Journal of Basic Education, 2004, 5(1): 43-50.

[3] S. Sukati, Y. Krisdinamurtin and M. Ance, The Relationship between morning food and The Learning Concentration of Bogor Elementary Shool Children, in Journal Nutrition and Food Research 1991, 14:60-73.
[4] J. L. G. Mariani, C. Anita, R. Anita, Risk Factors Analysis for Fatigue in Production Department Employees of PT Arwana Anugrah Keramik tbk, in Journal of Public Health Sciences, 2018 9(1): 5363.

[5] A. Sunita, The Basic Principles of Nutrition, Jakarta, Gramedia Pustaka Utama, 2009.

[6] K. Yuni, M. Niken, I. Sriyulan, Hemoglobin Levels and Intellectual Intelligence of Children, in Journal National Public Health, 2013, 8(3):117. 